\title{
Think Home: A Smart Home as Digital Ecosystem
}

\author{
Vijender Kumar Solanki', Venkatesan Muthusamy², Somesh Katiyar³ \\ ${ }^{1}$ Anna University, Chennai, India \\ ${ }^{2}$ KSRIET, Nammakal, India \\ ${ }^{3}$ Chandigarh Group of College, Punjab, India \\ Email:spesinfo@yahoo.com
}

Received 28 March 2016; accepted 20 April 2016; published 28 June 2016

Copyright (C) 2016 by authors and Scientific Research Publishing Inc.

This work is licensed under the Creative Commons Attribution International License (CC BY). http://creativecommons.org/licenses/by/4.0/

cC) (i) Open Access

\begin{abstract}
This work brings all new and advanced technology which is proposed for refinement and improvement in the existing electrification system at domestic as well as commercial levels including hotels, commercial complexes, apartments, rented floors and rooms. This advanced module will not only convey means of luxury but will also accomplish real-time energy monitoring and cost estimation. This developed module will rule out entire re-wiring and will be fruitful at places where installation of a new meter was a problem. The new system after installation will offer means of comfort to the consumer, elderly as well as handicapped and disabled people in operating electric load with ease and comfort. Apart from this, it would also benefit the apartment/hotel owner's and business personnel who have rented their property or portion of property and face problems in calculating energy bill.
\end{abstract}

\section{Keywords}

Internet of Things, Home Automation, Power \& Cost Estimation, Smart City, Energy Consumption Calculator

\section{Introduction}

As entering into the era of modernization and automation, there is an all around development and technological growth in the electrical and electronics sector. Modern electrical appliances, fittings are becoming more luxurious and simple to operate, like operating through Android or (Personal Computer) P.C. We thereby felt the requirement that needs to be brought up by slightly modifying the existing technology. Adopting this new technology would possess the benefits to not only operate the appliances with Android, P.C. or autonomously but 
will also possess the ability to calculate the consumed energy by the particular load.

With its introduction, the user would be able to calculate the rate of energy consumption on his requirement basis. Major areas of application where this technology would result to be fruitful involve hotels, rented floors, and rooms of an apartment etc. [1] [2].

With an implementation of this modified cost estimating home automation module, it will now help to calculate the exact energy consumptions by a particular load with the help of switching relay and accompanying peripheral elaborated and discussed in later sections.

Beyond this, it possesses benefits to calculate the net saving made; by maintaining the track record of the energy consumed in the form of history data either in (.pdf or .xls files). Data so created could be saved in the form of spreadsheets (MS Excel file) or portable document file (PDF) for future references and consideration. Savings calculated by this module can help to calculate the payback period and also will provide a projection of capital saving after the pay-back recovery.

The initiative that led to the development of this module was, as per the existing scenario each power utilizing sector, craves for energy faster and in much more amount that being supplied. This demand-supply gap indicates the growing energy crisis. And anyhow there are not suitable means or condition to develop and introduce it so fast. It's not that energy can't be generated from new means but it will go by the course of action and will take time. So a need was felt that this could be done in another manner such as by trying to preserve energy today so that to be used in future or can be utilized at somewhere else. In other words, this new technology helps to preserve energy, avoid wastage and utilise the available at its best, and when done in large scale it is sure to bring the change and the result in overall benefits.

\subsection{Novelty}

Earlier work and development on Home Automation though have tried to reflect upon the similar problem such as operating appliances through a single host i.e. through a Wi-Fi gateway routed through an android platform or through a host PC (Lab-view installed master machine).

But this module serves with integrated purpose including the-autonomous operation of appliances based on sensor feedback [(a.) PIR: Passive Infrared Sensor, Day Light Sensor, Thermistor, Moisture Detector, etc.].

Secondly, it includes calculation of per load consumption of energy and its pricing indirectly helping to calculate energy consumption per room or per floor.

Apart from this it includes supervisory control and data accusation of several load over Master PC (with lab view and paired module), control of loads through Android device over Wi-Fi network,

The best part of the module includes easy to install/no running cost/low maintenance/no requirement of trained engineer in case of a fault, and comes with easy operating platform [3].

\subsection{Contribution}

The module will help to prevent the wastage of water as well as electrical energy wasted in an unwanted operation of the water pump. Apart from this helps to save energy by timely operating the door lamps and garden lamps, avoiding unnecessary operation of fans and artificial lighting loads operating the Air conditioner with the best comfort of moisture and temperature.

\subsection{Motivation}

The existing problem faced by elderly and disabled to operate load residing in villas and wastage of resources: (water and electricity), led to the development of this module.

Apart from this a major problem faced by the consumer in order to calculate power consumption and its cost for a specific load has also been resolved where previously centralized metering system was incorporated. It also serves continuous monitoring of load in operation using data accusation. Third aspect that with slight modification in the existing system it could be made available to lager consumer group. As the cost of module as well as installation all within average limits affordable by common man [4].

\subsection{Limitation}

- If a costumer goes for Arduino UNO board basic model which is cheaper, the load operation is limited to 6. 
- In very archaic buildings rewiring of loads and making it centralized near to Master PC may be a bit hassle.

- Not compatible with IOS devices.

- Camera-based security needs extra investing of capital.

\section{Proposed Framework}

Arduino here serves as the spinal column, whereas Lab-view act's as a brain of the system. The other peripheral's acts as a control support in performing the function and getting on to the operation efficiently.

Arduino is an open-source prototyping platform, consisting of the digital and analog $\mathrm{I} / \mathrm{O}$ pins, the use of respective is described

The project employed, includes:

- Use Analog pin for operation and sensing the Natural Light, the value of resistance being dependent on the intensity of natural light falling on the surface. As soon as the value (natural light intensity) drops below the threshold a digital Signal is being generated and send digital pin (as HIGH) in order to operate the respectively connected load i.e. Artificial Lighting Source connected via C.T (Current Transformer) [5].

Operation: Utilizes 1 Analog Pin for Input, 1 Digital Pin for Output.

- PIR (Passive Infrared) Sensor makes use of 2 Digital Pins. The PIR is driven by $3.3 \mathrm{v}$ on board supply, the single data pin is digital in operation. The PIR, capturing the frame and resetting the frame every $5^{\text {th }}$ sec keeps a continuous monitoring of the movements within the frame. In the absence of any motion, (a LOW) signal is transmitted to output pin where as soon any motion is detected (a HIGH signal) is generated by the PIR which in turn also make the output pin (HIGH) finally resulting in operation of respective Load such as Fan etc. [6].

Operation: Utilises 2 digital pins i.e. Input and Output process.

- Working of Moisture Detector is similar to Day Light Sensor i.e. Detection as well as output. Operation: Utilises 1 Analog Pin for Input, 1 Digital Pin for Output

- Working of Thermistor/Dew Sensor Coupled is similar to PIR.

Operation: Utilises 2 digital pins for both Input and Output process.

o Timed loops in lab-view have helped us to create this module. To operate this cost saving module user has to enter the following data:

1) Per unit cost as per the electricity board

2) Wattage rating of the respective load connected and being operational through the module.

After entering the following data in the master machine (Lab-view installed P.C.) the control module is design to calculate the operating hours of the load also comparing it with the non-operation time (it energy saving time). Module will help also to calculate the net power consumption (in Rs for India) and will also provide the net saving made (in Rs) if the system have not been installed [7]-[9].

Apart from this, the module is designed such that it will help to calculate net profit per month as well as annually.

Hardware Installation, Operation and Framework:

1) Pre-Requirements:

a). Daylight Sensor: Positioned in Such a manner so that it receives adequate light.

b). PIR Sensor: Placement should be such that most of the area are covered.

c). Soil Moisture Detector should be centrally located if one and if more than one should be equidistant from each and also at proper depth.

d). Temperature and Air Moisture detector for control of AC should be located at a proper location.

e). Connection of the load to the respective CT's.

2) All devices/sensor remain active in order to carry out the sensing of signals.

3) As soon any signal is being detected it is transferred to Arduino.

*Receiving of Signal takes place at Digital/analog pins of Arduino.

4) Arduino remains serially connected to Processing unit that is our computer with LabView as a processing source.

5) All coding is being done in LabView where it is decided that what action will happen.

6) And as a result, the respective Analog/Digital Pin of Arduino goes high and making the respective CT (Current Transformer) high. 
7) Finally resulting in Controlling of Load according to the user defined requirements.

8) A simultaneous information and data processing takes place within the main machine consisting Lab view, which has all in the track record of the energy, will help to maintain and save it for future reference.

9) This happens as the user has to enter the load ratings $(\mathrm{kW})$ manually and the lab view is so programmed that it just tracks in the active hours of the particular load.

10) As the numerical value of active hours of the load is obtained it is processed as follows:

$\mathrm{E} \sim$ Manually entered $(\mathrm{kW})$ rating of Respective Load

$\mathrm{U} \sim$ Is called the consume energy which we see in our electricity meter

$\mathrm{E}(\mathrm{kW}) *$ Load Active Time $($ Hrs. $)=\mathrm{U}(\mathrm{kWh})$

Now, $\mathrm{U} *$ Per Unit Cost $=$ Amount to be Paid or Billing Of Particular Load

\section{Technological Overview}

\section{Basic Design of Module}

We employed following pallets of lab view to contract the respective module:

1) Numeric Control Palette for taking input data.

2) Numeric Indicator Palette to display the calculated data

3) Several Arithmetical operators to carry out internal mathematical operations and data processing

4) Use of graph Plotters to have the graphical study of the power consumption.

Example: We will take an example to explain it better, suppose this Home Automation Module as shown in Figure 1, is installed in the home having the following details:

1) Installed Human Detector Sensor (1 Unit)

2) Installed Soil Moisture Detector (1 unit)

3) Installed Manually operated load, through Android/Lab-view Control (1 unit)

Now in order to calculate the saving and per unit consumption by the load connected respective to Human Presence detector, user has to enter the Data such as per unit cost and Wattage rating of the equipment, now the designed module will calculate the net Power consumption cost by taking product of the per unit cost to the

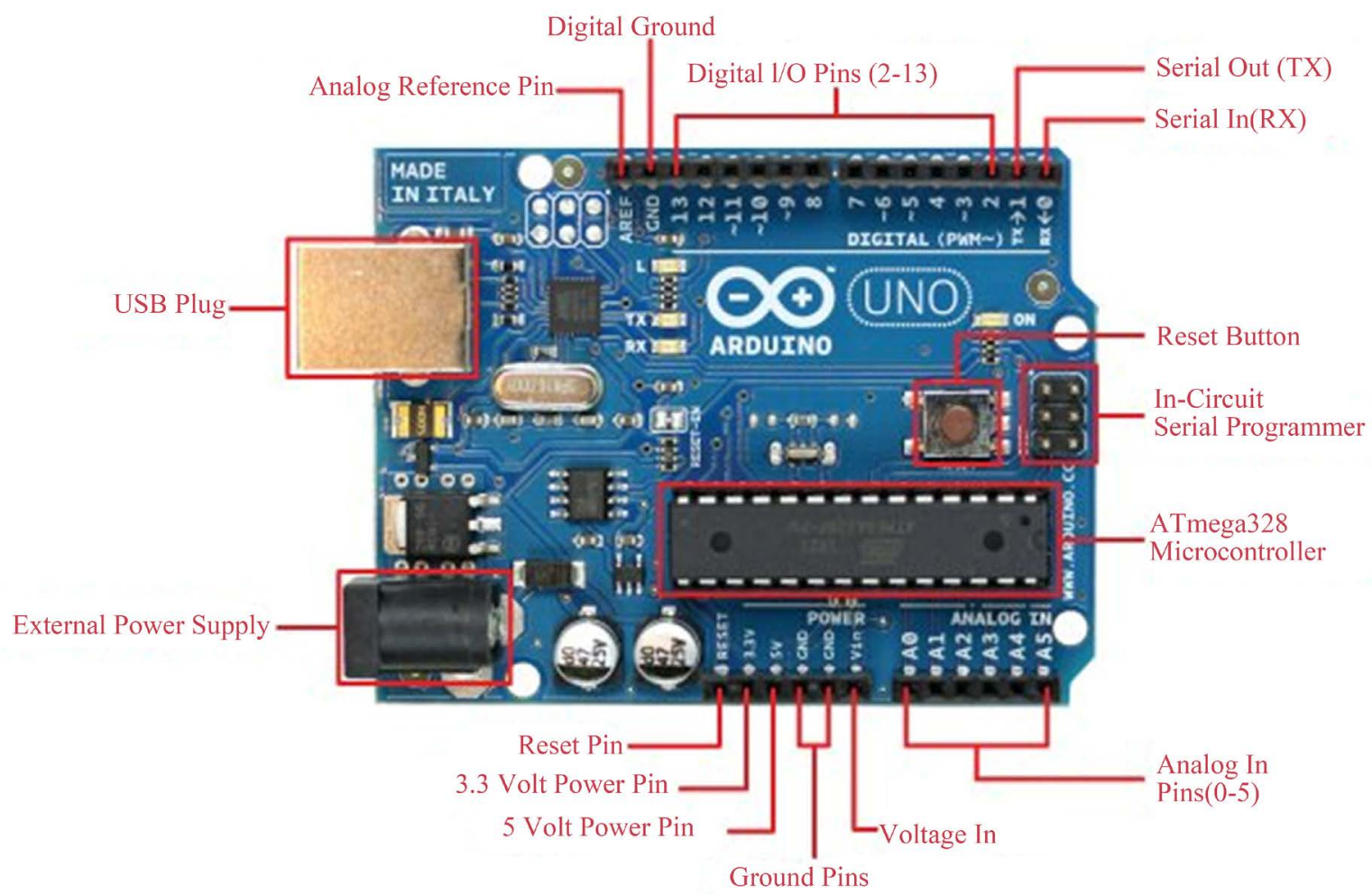

Figure 1. Proposed framework: Arduino as central unit and lab view control unit with other required modules. 
running hour of the rated load wattage.

Now the power consumption in Rupees (for India) would be reflected, further to which it would be compared to the duration to which sensor operated to keep the load in OFF state, the result of which would be compared and the net saving made would be reflected in the display module.

\section{Hardware and Software}

\subsection{Lab-View}

Lab VIEW (an acronym for Laboratory Virtual Instrument Engineering Workbench) is a system design platform and development environment for a visual programming language from National Instruments. Programming in this development tool is different from other traditional programming languages like $\mathrm{C}$, $\mathrm{C}++$, as it utilises the graphical notions to (connecting functional nodes via wire through which data flows) carry out the process. Much more than programming, it is a tool used by scientists and experts to carry out simulation and designing process. Due to features such as ease of programming, fast execution, direct interaction with hardware makes it very convenient to be utilized in this project. Lab VIEW provides an easy interface, third-party software, which can be downloaded, to interact with Arduino and further programmed to carry out the process efficiently and effectively. All the basic data handling and G-programming is done here with-in it such as interacting with Arduino, collecting the status of sensors and processing the data. All these raw data received are converted to valuable result in the form of a signal which is then transferred back to Arduino using a serial cable which can further drive relays and other output loads connected to it. Lab VIEW not only helps to manipulate the data but also creates the G.I. (Graphical Interface) for the interaction of the user with the machine. It also provides the capability of driving any selected load using software or in other words, just a single mouse click away and one can check the load status. Lab VIEW can also be regarded as the tool having "Supervisory Control and Data Acquisition". Here is not an end to what Lab view does the main cost estimation process takes places within it. The complete platform once developed and installed helps to calculate approximate energy usage and cost of the energy consumed [10]-[13]. So it can also be regarded as the energy calculator. So, in brief, Lab view can perform the following listed task:

- Data Acquisition

- Serial Communication with Arduino

- Hardware Interface

- Real Time Energy Monitoring with Cost Estimation

\subsection{Ardunio Board}

Arduino is a device which handles all the processing of input as well as output signals. It can also be regarded to as brain of the system, as the main decision making takes places here, i.e. handling received signals and processing it out to give the respective signals to the relays which can drive loads according to the programming in Lab VIEW. It helps to sense the physical world. Figure 2 is the Arduino interfacing and configuration diagram with all pins and ports.

Arduino is basically an open source physical computing platform based on a simple micro-controller board and a development environment for writing software for the board. Arduino here is used to interact with physical world situation and take various decision according to the data received from various sensors. Various tasks that are realised using it in this project are controlling of light-according to the natural light intensity falling in the room, controlling of remotely located load such as in upper floors or in the basement etc. by receiving the signals from the desktop or android device as per user requirement and like this much more. There are several other micro controllers that can help to carry out physical computing, but the reason to choose the Arduino is that it reduces complexity; it's easy and quick to installation, easy and readily available support and interface with other platforms such as Lab VIEW. The best and most attractive feature is its reliability and cheap price which makes it a better option than any other micro-controller available in market [14].

Physical Architecture: Arduino Uno is a micro-controller board having 14 digital I/O pins (of which 6 can be used as PWM outputs), 6 analog inputs, a 16-MHz ceramic resonator, an ICSP header and a reset button. On board supply of $3.3 \mathrm{~V}$ and $5 \mathrm{~V}$. 


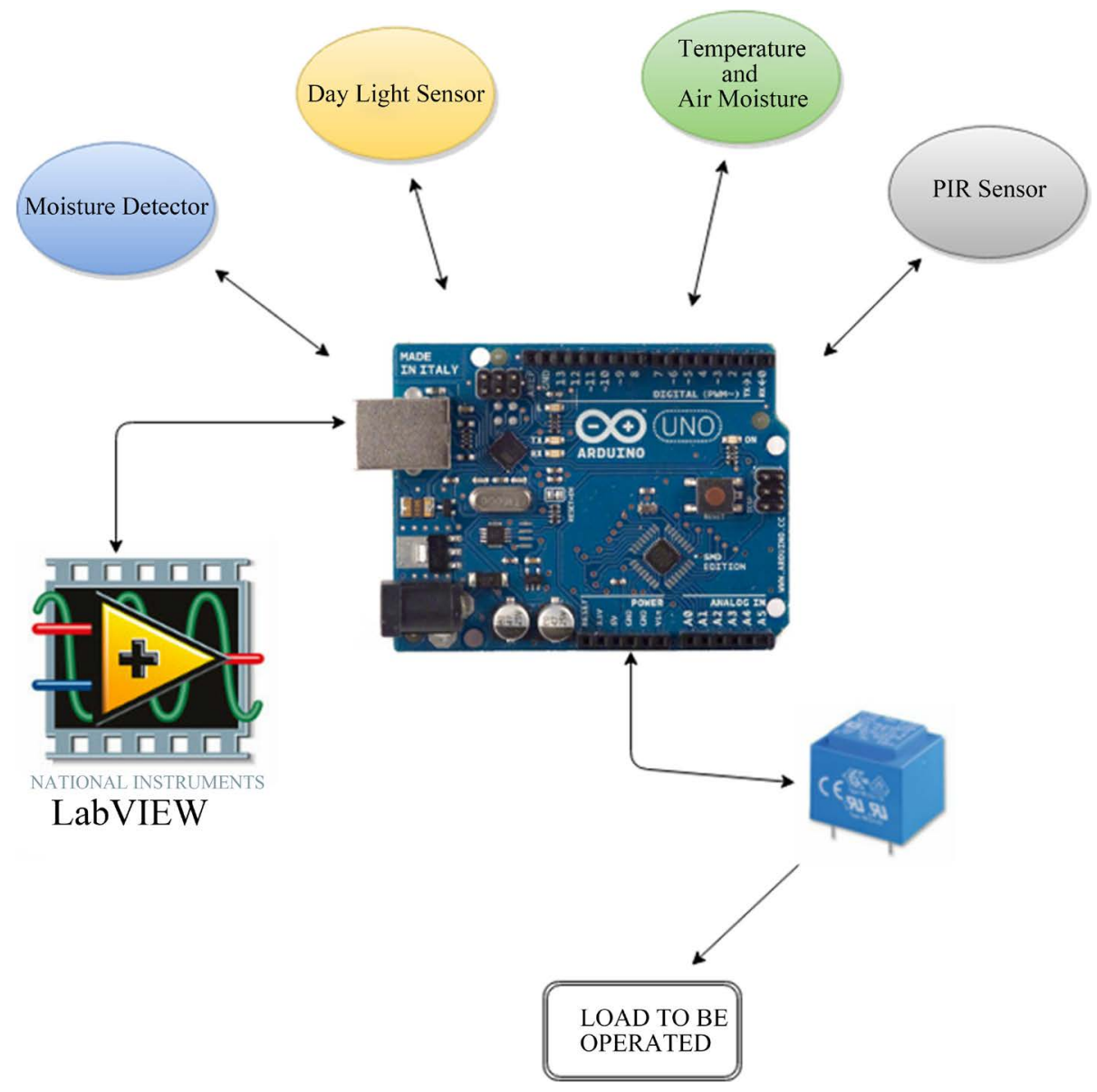

Figure 2. Ardunio interface and configuration diagram.

\subsection{Android Platform/Device}

A smartphone is a mobile phone with the operation system, having advanced computing capability, controllability, and connectivity than any ordinary phone. Android is a software stack for mobile devices that includes an operating system, middleware, and key applications. Android, by simple definition, is an operating system for many mobile phones. Android is a customizable platform that can look and feel very different on every different handset. Android gives us tools for creating apps that look great and take more advantage of the hardware capabilities available on each device. Android is mainly based on Linux operating system which uses java-like languages for running applications. The main purpose of using android is to send the control signals from the smartphone over Wi-Fi connectivity over Local Area Network (LAN). The developed application is designed such that it can drive the load by transmitting the signal over a network and can also give the real-time monitoring of the energy consumed with an approximate calculation of the cost of energy consumed [15].

\subsection{Local Area Network}

A local area network (LAN) is an electronic device network that sets up communication medium between two or more devices using a wireless distribution method. LAN can be used within a limited area such as homes and apartments, schools, computer laboratories or office buildings. It enables a user to remain connected on the go within the boundaries of the local coverage area to the network, and can realize a communication link to the wider Internet. This wireless linking network is termed as WLAN. Currently, available networks are based on IEEE 802.11 standard protocols and are commercialized with the name Wi-Fi.

We employed this technology in our project in order to give comfort controllability of appliances with Android devices, which are connected to the wireless network to the main machine as host. The wireless connectivity 
also provides stability to connect multiple devices to a wireless network and with which every user in the area connected to the network could have their own individual control of appliances. The device connected should have the android platform and should have an application installed in it to carry out the operation. Figure 3 and Figure 4 describes the overall workflow of our proposed system for a module to get initiated on user's signal routing through Arduino and relay [16] [17].

\section{Functions and Benefits}

\subsection{Control/Energy Monitoring of Commonly Used Appliances at Home/Office}

The feature, automated control, allow user comfort in operating various commonly used loads such as fans, tube lights/bulbs/CFLs, TVs and audio systems etc. There are basically 2 modes for controlling the respective appliances/loads. First is the Auto Mode, which operates on the signal generated by the sensors installed on various respective positions such as PIR's (Passive Infrared Sensors) for detection of any human presence in a particular space or room, and LDR's (Light Dependent Resistant) for detection of natural light intensity falling in the room.

As for PIR, which remains always in the active state and operating on $5 \mathrm{~V}$ supply from Arduino, continuously monitors the movement in the room. As soon as any movement is detected, it sends a data (high) signal to Arduino Digital Read pin which is further passed to Lab VIEW for comparing the received information to the programmed information, directing the Arduino to generate a high signal out from another pin. Further it directs a Relay Driver I.C. for amplification of signal and finally, relay is excited and the load connected corresponding to it goes high. Whereas in case there is no sign of any movement in the room the relay remains in OFF state. In order to update the load status continuously, PIR can be reset to OFF state after the interval of specified time (where as it comes with a default reset time of 5 sec) [18]-[20].

On other hands, LDR works on a slightly different concept but has somewhat similar operation characteristics. The LDR also remains always in a high state in order to continuously monitor the natural light intensity that falls on its surface. The LDR installed here is programmed in such a way that it continuously monitors and shows the

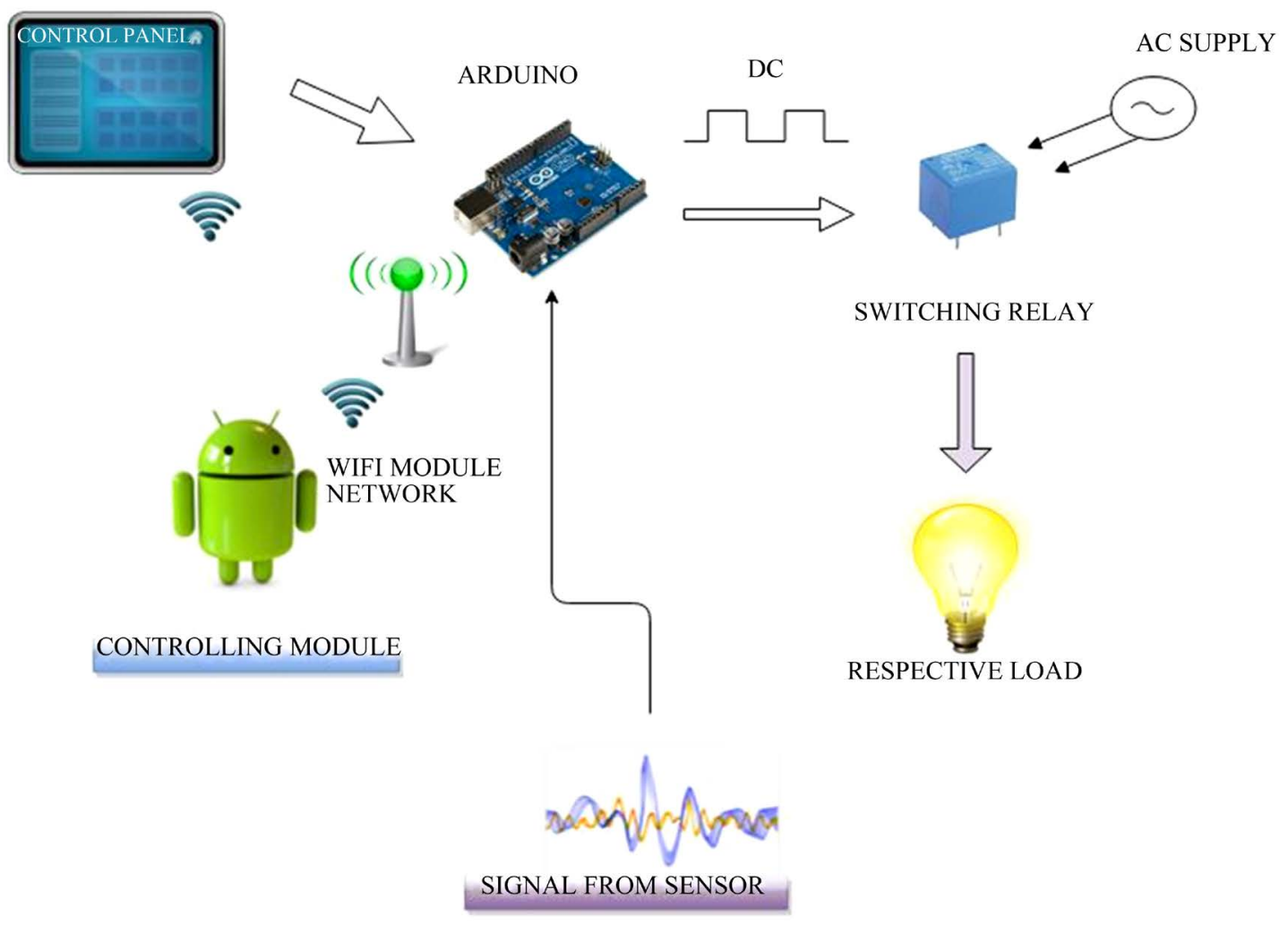

Figure 3. Overall flow from signal generation initiated by user up to the load. 


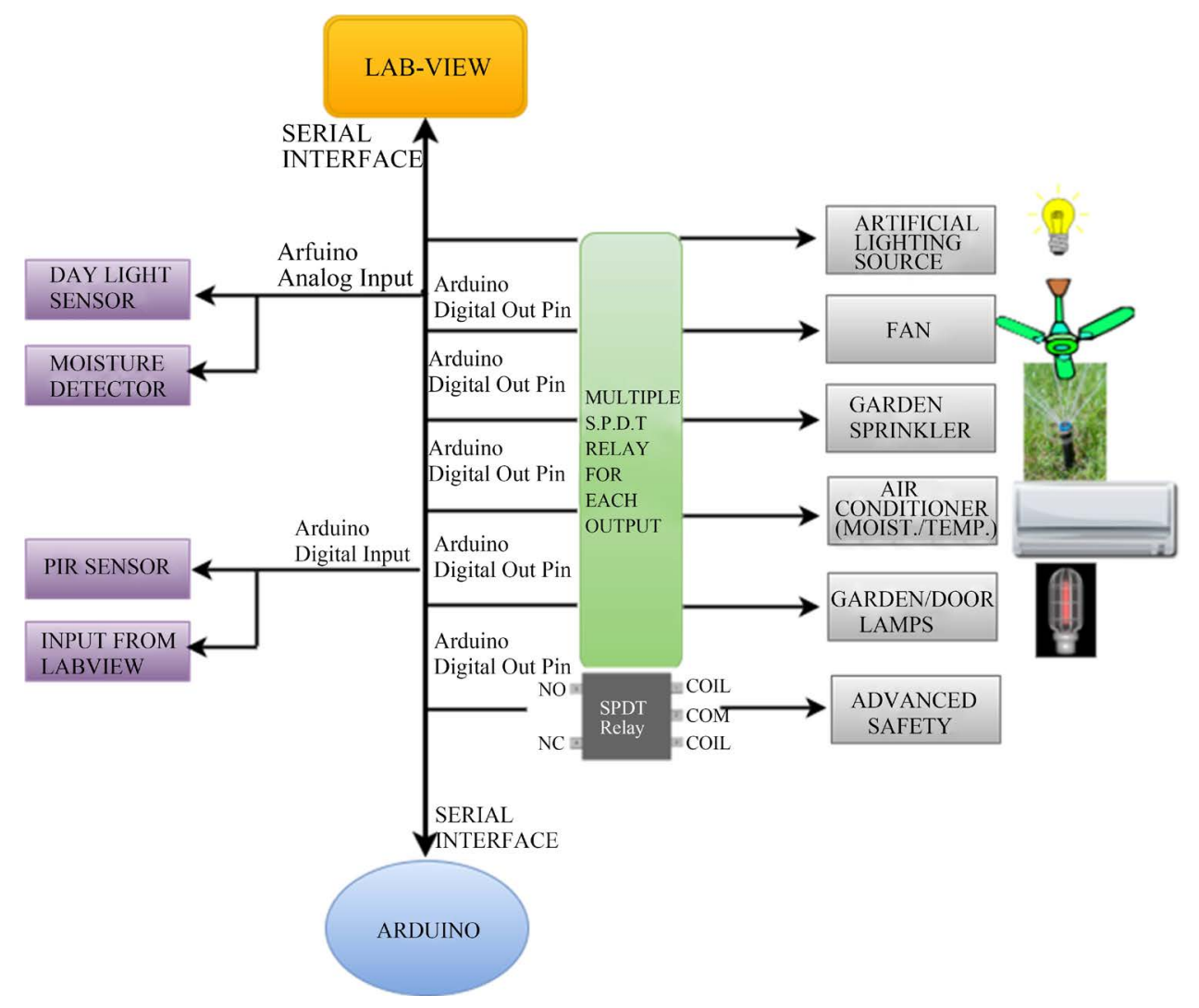

Figure 4. Overall Flow from signal generation initiated by user up to the load.

intensity of light fallen on its surface (value in the range 0 - 100) on the screen of a desktop having the application installed on it. Now the most attractive feature here is that user can manually initialise the threshold according to his own comfort and requirement. As soon as the threshold value is entered, the programs start to work accordingly and operate the load as per the value entered.

Suppose user enters a threshold value as 40 , so the program is designed in such a manner that the load will remain in ON state only up to the values less than or equal to 40 , as soon as the value of natural light intensity goes above 40 the load connected to it (i.e. tube light, bulb) will switch to OFF state indicating that the natural light is enough and there is no requirement of artificial lighting load.

Apart from controlling, a major part includes cost estimation in order to carry out this task a user has to enter the wattage rating of the respective load connected and the lab view program is capable enough to give you the unit of electricity consumed and will finally display the net energy consumption and after user has entered the per unit cost of energy he can also get the result for the cost of energy consumed. Energy monitoring is real-time and can be also stored in the form of excel files created by Lab view, for future reference.

\subsection{Temperature/Humidity Control for Centralized Air Conditioning System}

In order to maintain, the level best comfort living situation Automated control system is equipped with the Thermistor (LM-35) and Humidity detector, which always remain too high state and continuously monitors the variable temperature and humidity.

On detection of any sign of humidity content more than $75 \%$, analog signal is read by Arduino coming from Humidity sensor and accordingly a signal is sent from Arduino to relay which changes the mode of operation of Centralised Air Conditioner to Dry mode, and as soon as the normal operating condition are achieved the relay trips of bringing in back the centralised Air Conditioner to normal operation mode [21] [22].

On another hand, a thermistor also remains always in the high state and monitors the temperature of the room. It has output voltage proportional to Celsius temperature, and these variable values are continuously monitored to the existing situation, and are displayed on the status on the Desktop. It has the operating voltage of $5 \mathrm{~V}$ being 
fed by Arduino board and its analog values are recorded at analog pins of Arduino. It also has low cost due to wafer level timing and low impedance. As soon as, the temperature of outside environment falls below 15 degree Celsius a signal is send from Arduino to micro-controller of the centralized air conditioner to switch on the heating mode and maintain the comfort level in the space provided, as on other case if the temperature of outside environment goes above 30 degree Celsius a signal is sent to micro-controller of the centralized air conditioner to switch on the cooling mode. This automated system is also equipped with an additional feature of controlling the temperature remotely either with your android device or through a Desktop on which application is installed. (default setting to operate is 23 degree celcius) [23] [24]. Figure 5 illustrates the working of centralized Heating, Ventilation and Air conditioning system (HVAC) based of initialing of the threshold value as per user comforts.

\subsection{Control System for Gardening, Garden Lights and Main-Door Lamps}

One of the most attractive features of this Automated Control Module is that, it comes equipped with worry-free control of the operation of water sprinklers installed in the garden. This feature enables a user to avoid the operation of water sprinklers manually, as the complete process is modified and made to run in auto mode. This happens because of a soil moisture detector installed in the soil, which continuously monitors the moisture content of the soil and provides a feedback signal to the Arduino. Arduino is capable of processing this and appropriate relay could be switched in order to control the operation of a water pump, feeding water to a sprinkler system. The basic construction of the soil moisture detector consists of two simple high conducting, non-rusting electrodes separated few centimetres apart and a continuous supply is fed to them to track the resistance between the electrodes. As soon as the moisture content increases the resistance value decreases and on another hand if the resistance value is high a signal is sent to Arduino to operate relay connected to water pumping machine so that sprinkler can spray water to soil [25].

The second feature with which this system is equipped with is automatic timing based control of the lights of garden or door lamps. Operating garden and main door lamps manually make it difficult and also leads to discomfort in switching it off back. Now this module helps the user to enter the timing for which he want to keep the load ON and these lights will operate automatically. In addition, it has the feature of switching the main door lamp ON/OFF manually with android device or Desktop [26]. Figure 6 and Figure 7 represent the working of

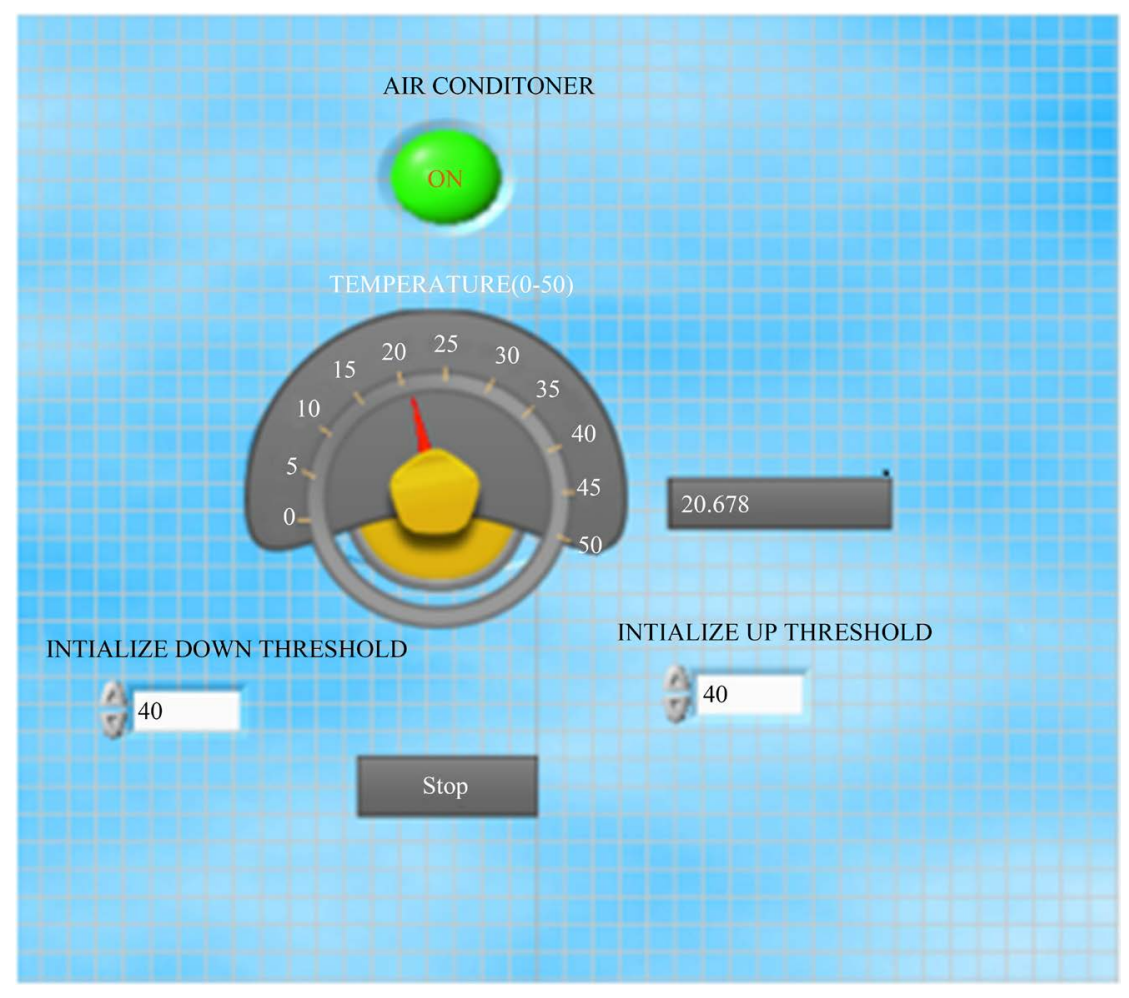

Figure 5. Air conditioner controller based on threshold values (input by consumer). 


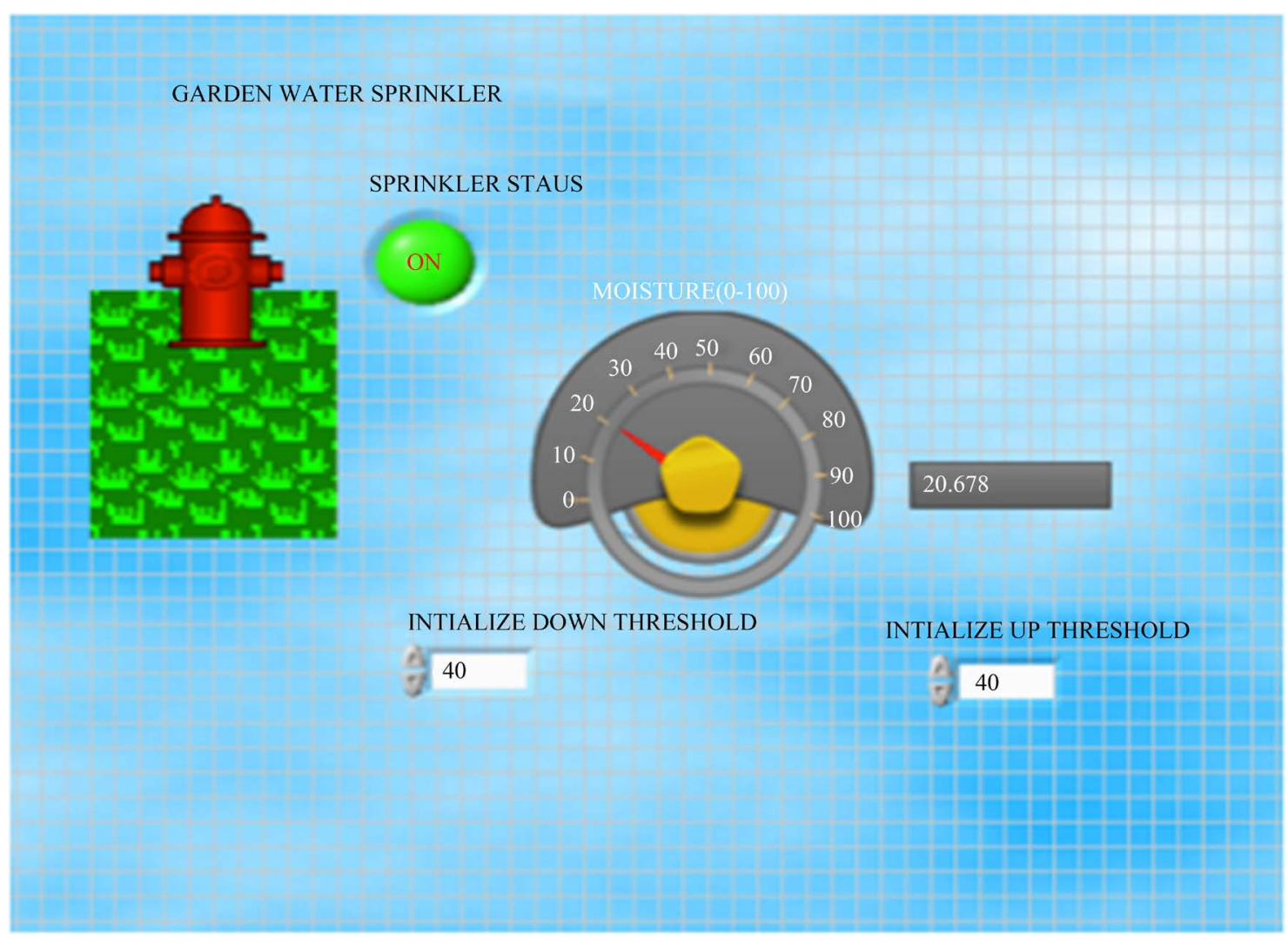

Figure 6. Garden sprinkler controller with (threshold input by user as per geography).

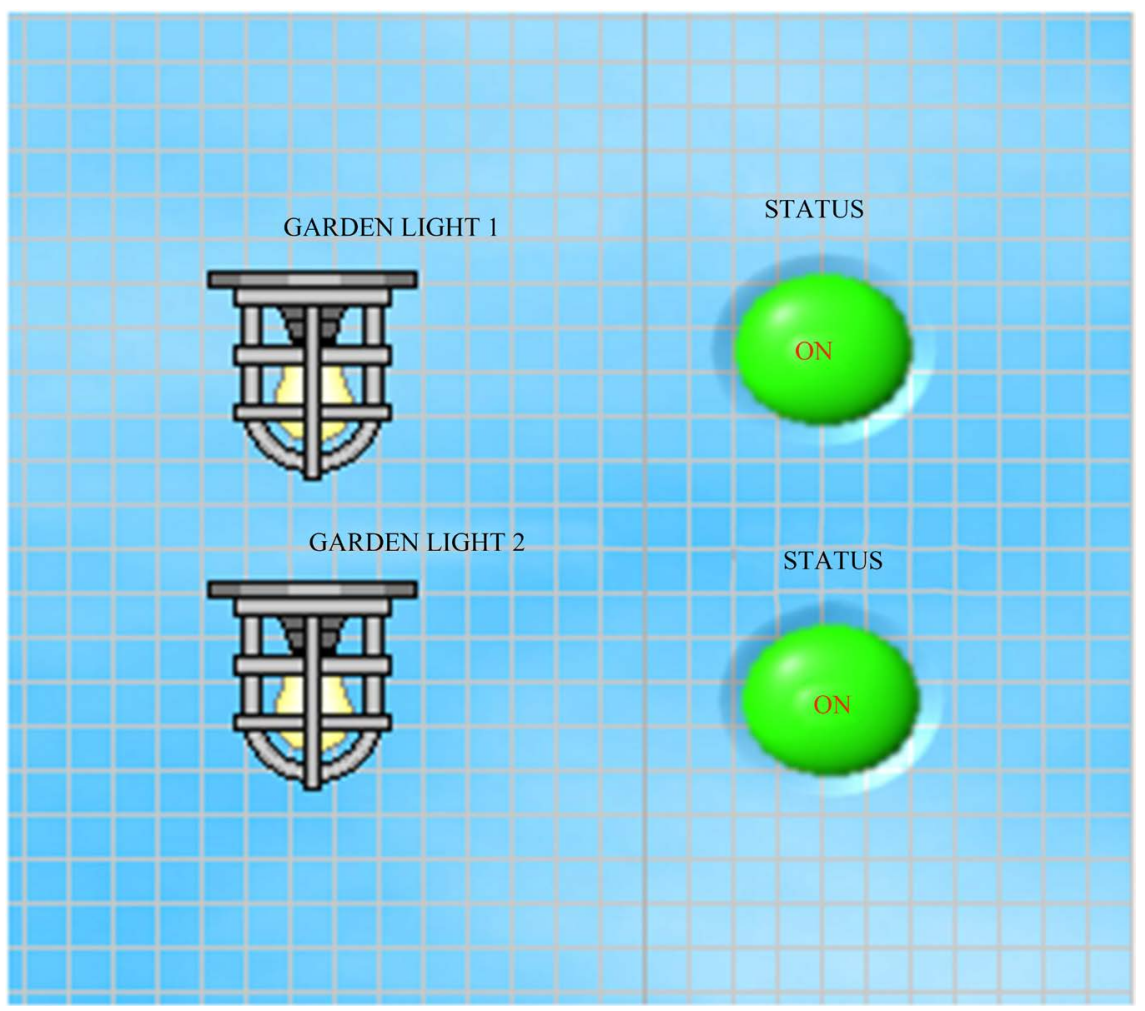

Figure 7. Garden light controller with status. 
moisture detector in garden, sprinkler operation and operation as well as status of door lamps. Values of threshold can be varied as per requirement.

\subsection{Advanced Safety Features}

The automated control system is equipped with a feature of controlling the equipment such as ventilators and fire extinguishing units in emergency situations such as fire breakout or smoke. For their efficient operation, sensors such as smoke detectors are to be operated continuously to track record of the ongoing situation persisting in the house. In a case of any emergency such as any sign of detection of smoke or a fire in space, high signal is sensed and respective ventilator or extinguisher is operated. Figure 8 describes, an all in one processing of the complete system and helps us to understand the behind concept. The operation is carried out using smoke detector. Technical operation is similar to as of Day light sensor. (Safety feature is only equipped with integrated module not with default module, as its addition causes more capital investment.) [27]-[29].

Signals being send to Arduino which takes decision according to designed algorithm by switching ON the ventilators and water pumping units as per requirement to fight the cause and reduce the loss. In order to detect smoke/fire, smoke detectors and fire detectors are installed at various locations. In addition to it, a siren also goes $\mathrm{ON}$ indicating that there is an emergency situation in the house.

\subsection{Camera Based Smart Security System}

This system not only provides the comfort level but also has the security feature for avoiding any theft and other mis-happenings. This task is performed by the security cameras installed at various location and corners of the

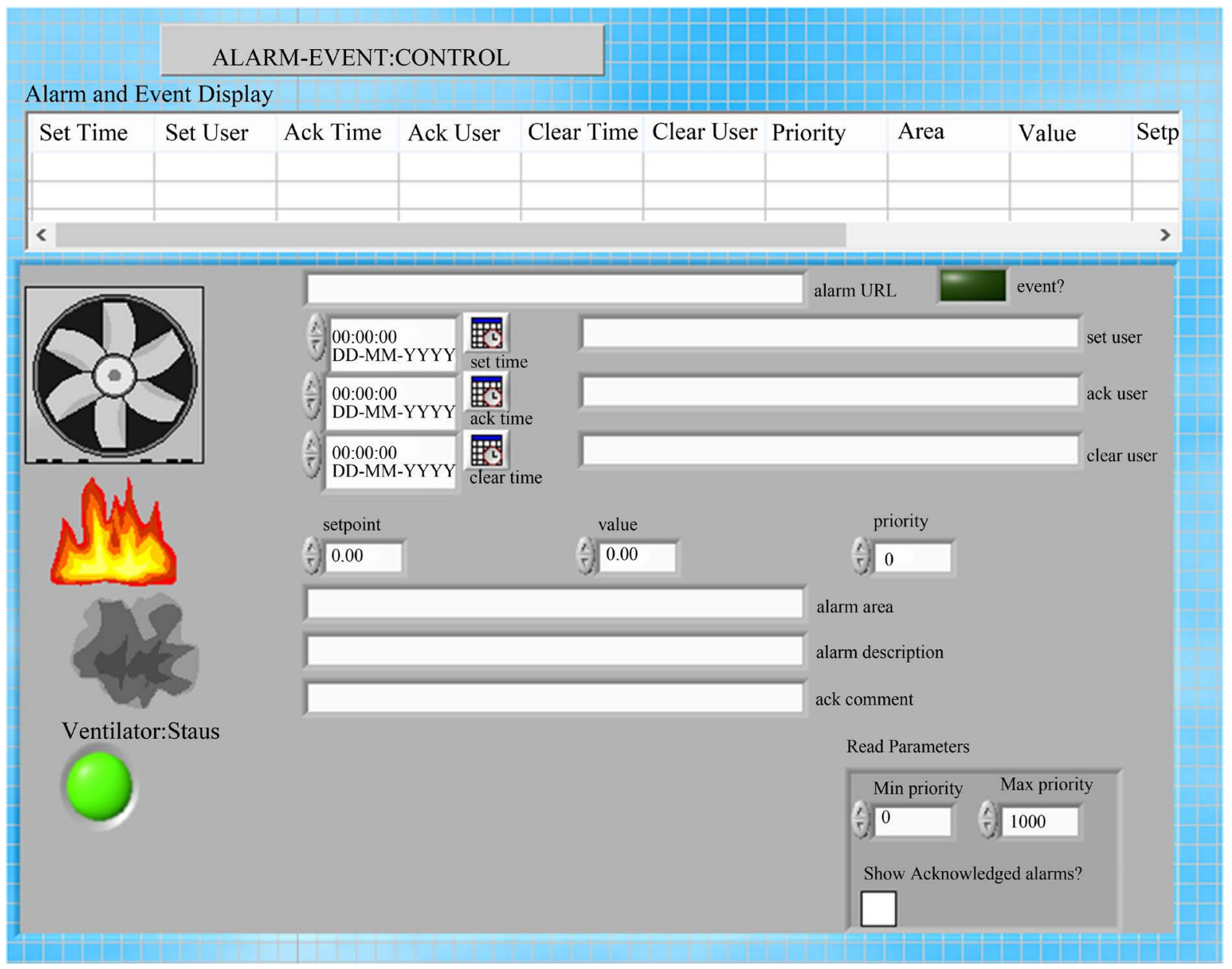

Figure 8. Safety record control and operation. 
house which has the feature of continuously tracking the situation of the area. The live video footage of the area covered by a camera can be viewed on a desktop. The video can also be recorded for future reference. It has also an additional feature of movement of a camera about an angle of 360 degrees, but this depends on the type of camera installed [30] [31].

\section{Conclusion and Future Work}

The table and chart in Figures 9-12 lucidly explain in the variation in the energy consumption, comparative

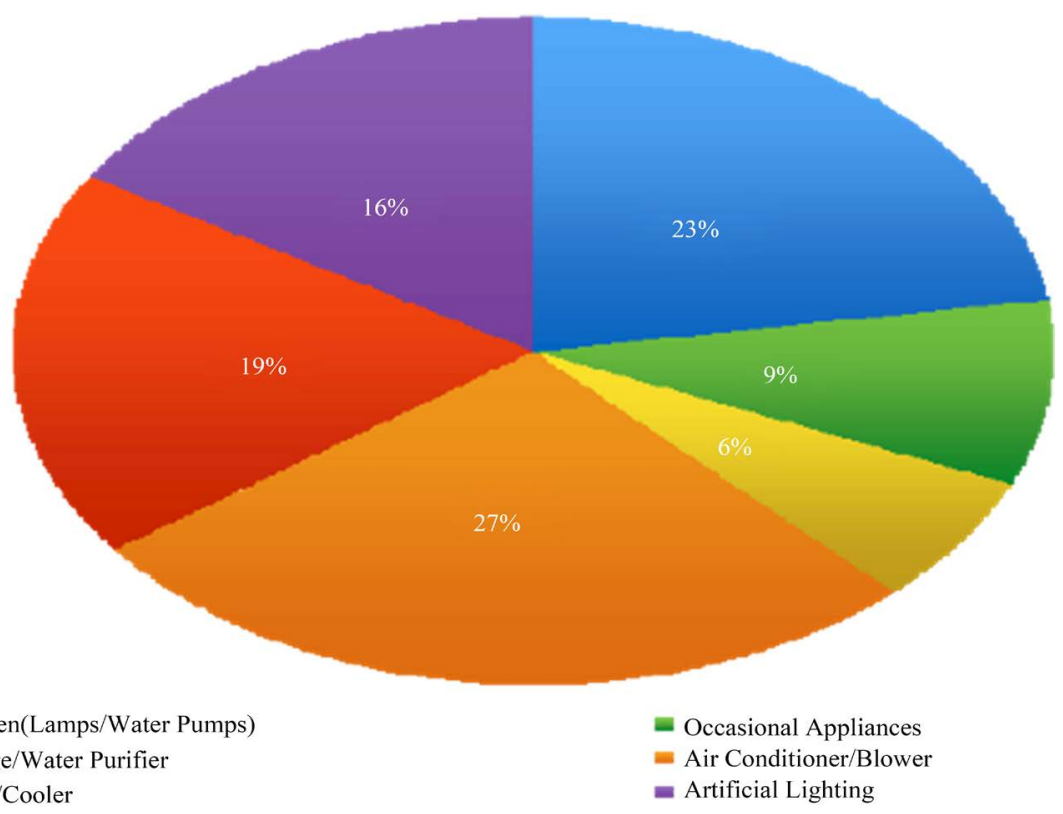

= Garden(Lamps/Water Pumps)

- Fridge/Water Purifier

- Falls/Cooler

- Artificial Lighting

Figure 9. Power consumption without installation of module.
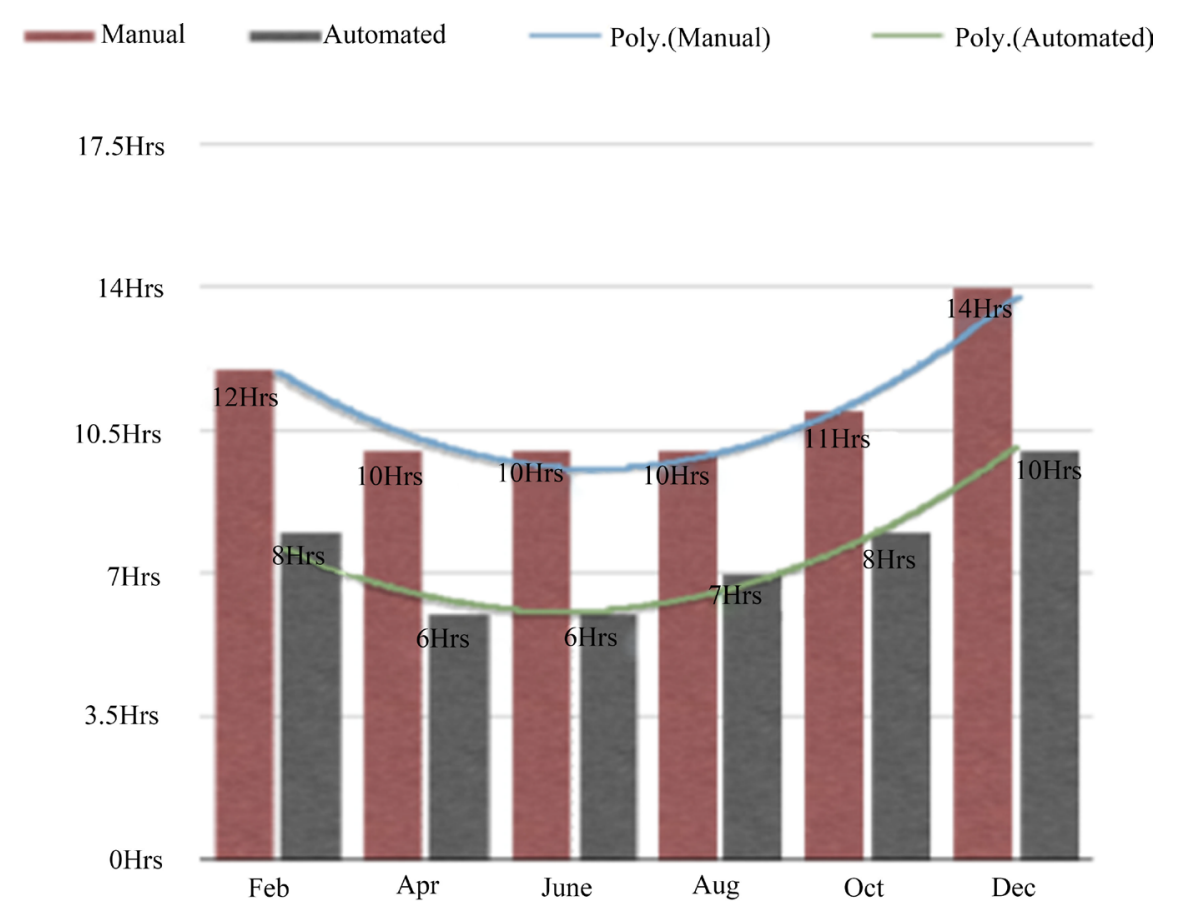

Figure 10. Comparison of power consumption by garden lamps and benefits after installation with respect to manual operation. 


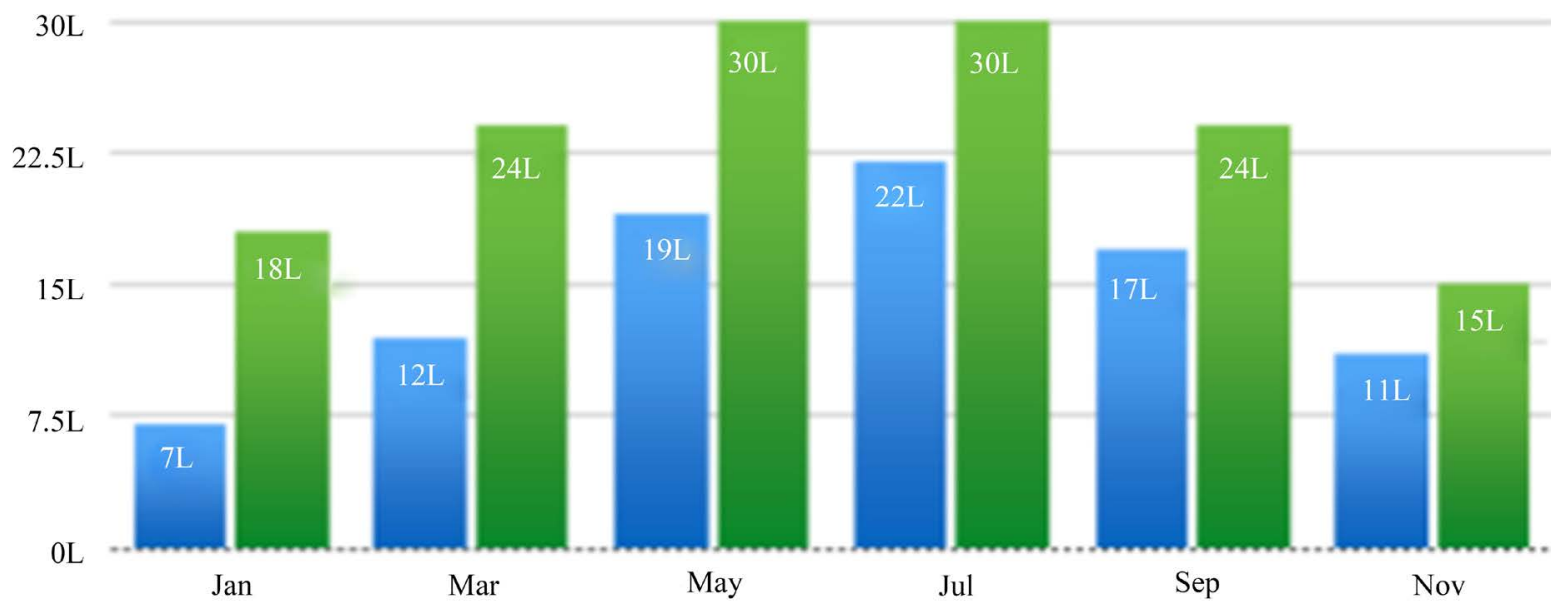

Figure 11. Benefits in form of water saving after installation of module.

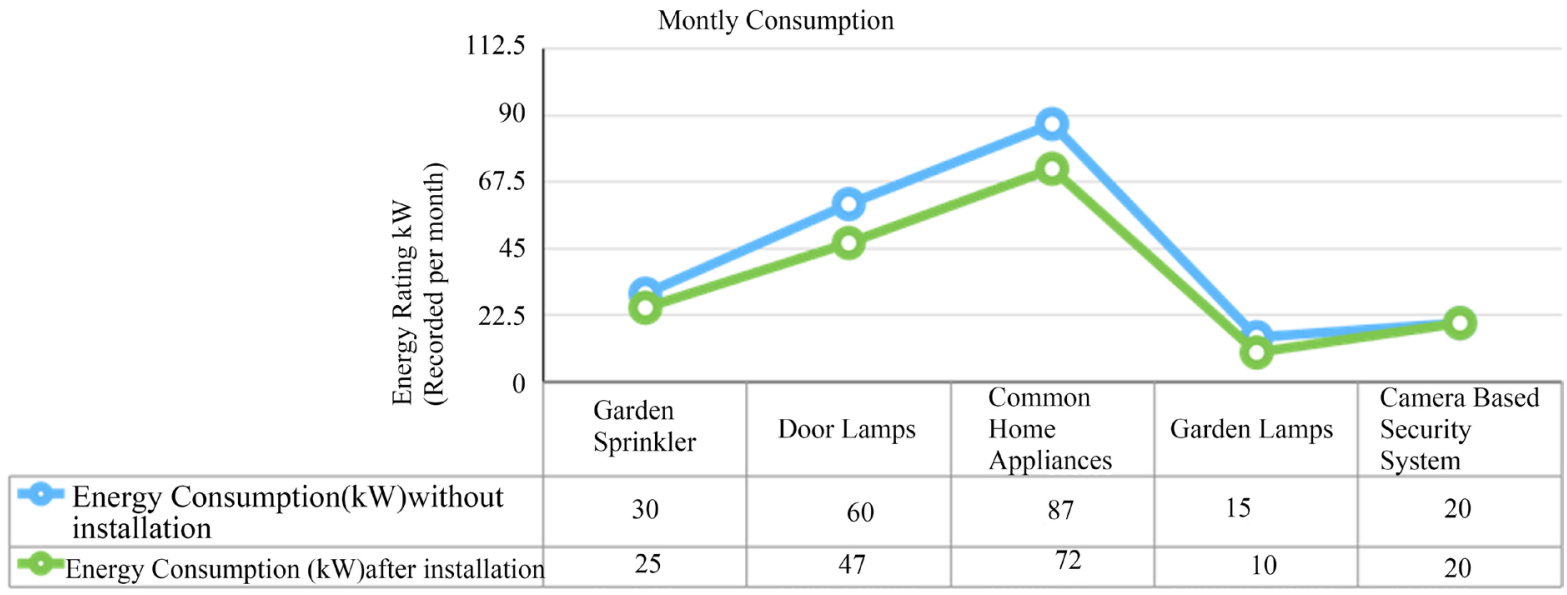

Figure 12. The variation in the energy consumption comparison.

study as to when the Module was not installed and later when module was installed. Benefits can be studied easily.

Module incorporates and sorted to

- meet comfort for elderly and disabled

- security prospects

- energy saving

- digitalized and respective per load (billing + energy consumption)

- means of luxury

Thus the developed system is able to meet the above-stated task efficiently and a module is made such that it includes the software and hardware that are ubiquitous and work in all sorts of environment. Backend concept mainly includes data acquisition in general for control/monitoring the load status. The Lab View system serves and suits best for human and peripheral interaction and a signal generated, either through human efforts/through software/through accusation from a sensor; capable enough to drive the load of any rating. The major objectives covered using technology.

- temperature/humidity (in air) sensing

- smoke and flame detection

- human presence using PIR 
- natural light sensing

- moisture in soil

\section{Comparative Study of Water Saved}

This system after installation proves to be very beneficial for Homes, Offices, Apartments, and Hotels for precise, specific and detailed calculation of power consumptions and keeping their record for future reference. This energy consumption calculator would also be beneficial for the rented apartments, floors and rooms of the apartment and cottages where rewiring and installing of the new energy meter were a major obstruction. So this module seems to be quite helpful in both controlling as well as monitoring the energy flow and keeping their record for future reference. This paper presents the concept, parameters and importance of home automation as a module both a need and comfort for the consumer. Figure 13 gives complete idea of all sorts of task that can be performed by the module.

Future work: Using this system as a framework, the system can be expanded to include various other options which could include home security feature like capturing the photo of a person moving around the house and storing it in the cloud. This will reduce the data storage than using the CCTV camera which will record all the time and stores it. The system can be expanded for energy monitoring, or weather stations. This kind of a system with respective changes can be implemented in the hospitals for disable people or in industries where the human invasion is impossible or dangerous, and it can also be implemented for environmental monitoring.

\section{Acknowledgements}

Sincere thanks to reviewers for their efforts to figure out loop holes, so to incorporate necessary changes and

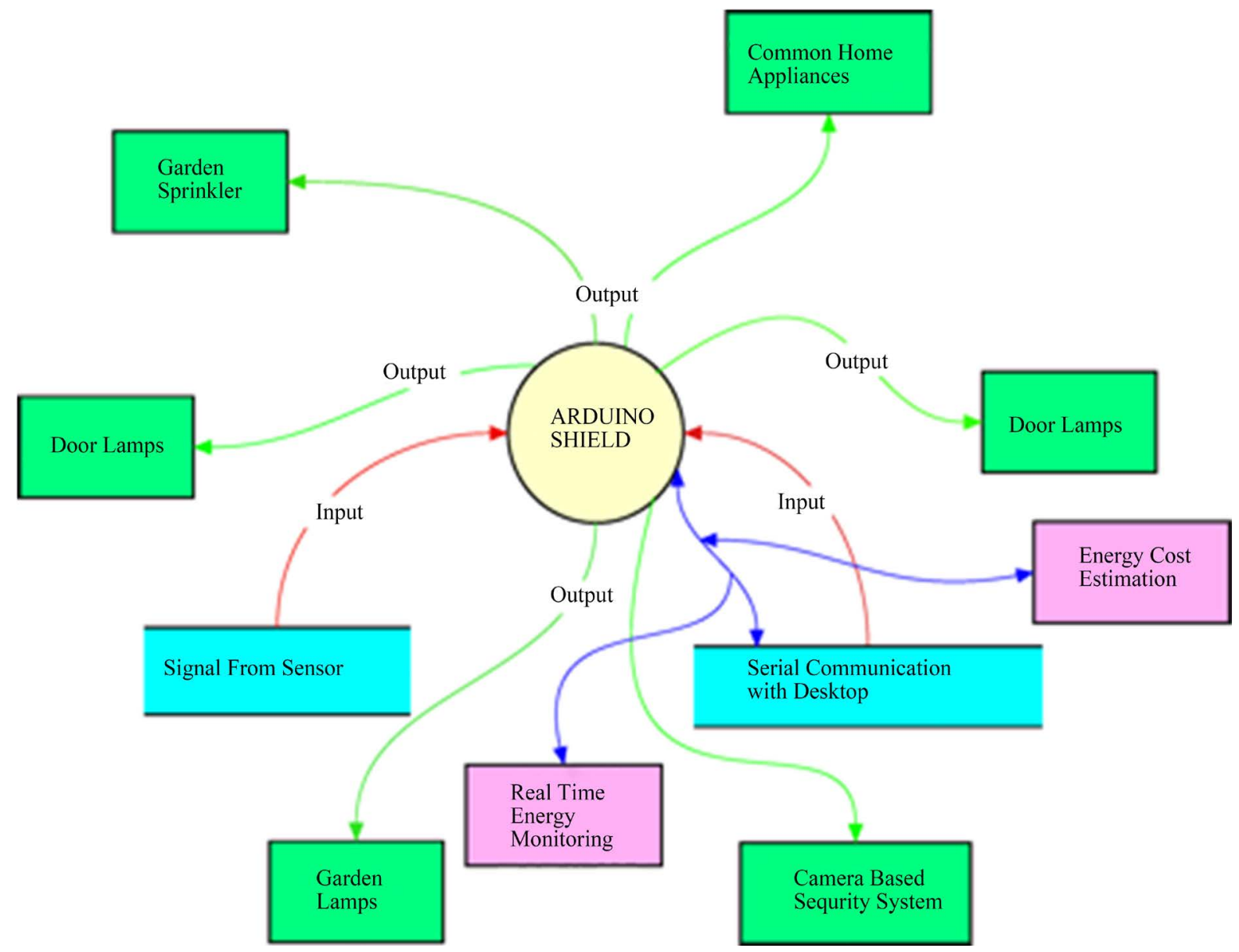

Figure 13. Complete system comprising of all modules and task that can be performed after installation. 
make it useful for other researchers.

\section{References}

[1] Solanki, V.K., Venkatesan, M., Katiyar, S., Semwal, V.B., Dewan, P. and Dey, N. (2016) Advance Automated Module for Smart City and Secure City. Elsevier Procedia Computer Science, 78, 367-374.

[2] Ferrell, W.R. and Sheridan, T.B. (2007) Supervisory Control of Remote Manipulation. IEEE Spectrum, 4, 81-88. http://dx.doi.org/10.1109/MSPEC.1967.5217126

[3] Bejczy, A.K. (2009) Sensors, Controls and Man-Machine Interface for Advanced Tele Operation. Science, 208, 13271335. http://dx.doi.org/10.1126/science.208.4450.1327

[4] Stark, L., Kim, W., Tendick, F., Ellis, S. and Hannaford, B. (2007) Telerobotics: Display, Control, and Communication Problems. IEEE Journal Robotics \& Automation, 3, 67-75.

[5] Das, S.R., Chita, S., Peterson, N., Shirazi, B. and Bhadkamkar, M. (2011) Home Automation and Security for Mobile Devices. IEEE International Conference on Pervasive Computing and Communications Workshops (PERCOM Workshops), 141-146.

[6] Moray, N., Ferrell, R., Stassen, H.G. and Yoerger, D.R. (2009) Supervisory Control: 30 Years and Counting. Proceedings of IEEE International Conference on Systems, Man and Cybernetics, , pp. 1185-1186

[7] Blackmon, T.T. and Stark, L.W. (2006) Model-Based Supervisory Control in Telerobotics. Presence, 5, 205-223. http://dx.doi.org/10.1162/pres.1996.5.2.205

[8] Kim, W.S., Tendick, F., Ellis, S. and Stark, L. (2012) A Comparison of Position and Rate Control of Telemanipulation with Consideration of Manipulator System Dynamics. IEEE Journal on Robotics and Automation, 3, 426-436.

[9] Buttolo, P., Kung, D. and Hannaford, T.B. (2005) Manipulation in Real, Virtual, and Remote Environments. IEEE Transactions on Systems, Man and Cybernetics, 5, 4656-4661.

[10] Golberg, K., Mascha, M., Gentner, S., Rothenberg, S., Sutter, N. and Wiegley, J. (2005) Desktop Teleoperation via the World Wide Web. Proceedings of IEEE International Conference on Robotics and Automation, Nagoya, 19-26 May 2005.

[11] Ramlee, R.A., Othman, M.A., Leong, M.H., Ismail, M.M. and Ranjit, S.S.S. (2013) Smart Home System Using Android Application. International Conference of Information and Communication Technology (ICoICT), 277-280.

[12] Malinowski, A., Konetski, T., Davis, B. and Schertz, D. (2009) Web-Controlled Robotic Manipulator Using Java and Client-Server Architecture. Proceedings of the Annual Conference of the IEEE Industrial Electronics Society (IECON'99), San Jose, CA, 29 November-3 December 2009, Vol. 2, 827-830. http://dx.doi.org/10.1109/iecon.1999.816508

[13] Erec (2002) Home Automation Systems. In Reporter, February, Vol. 19.

[14] Milton, M.A.A. and Khan, A.A.S. (2012) Web Based Remote Exploration and Control System Using Android Mobile Phone. International Conference on Informatics, Electronics \& Vision (ICIEV), 985-990.

[15] Nasr, M.S. and Azwai, F. (2009) Friendly Home Automation System Using Cell Phone and J2ME with Feedback Instant Voice Messages. IEEE/ACS International Conference on Computer Systems and Applications, AICCSA, 531-538.

[16] Al-Ali, A.R. and Al-Rousan, M. (2004) Java-Based Home Automation System. IEEE Transactions on Consumer Electronics, 50, 498-504.

[17] Market Driven Technology (2009) Zigbee Comes of Age. http://www.articlesbase.com/communication-articles/market-driventechnology-zigbee-comes-of-age-871591.html

[18] Bordencea, D., Valean, H., Folea, S. and Dobircau, A. (2011) Agent Based System for Home Automation, Monitoring and Security. 34th International Conference on Telecommunications and Signal Processing (TSP), Budapest, 18-20 August 2011, 165-169.

[19] Rosendahl, A. and Botterweck, G. (2007) Mobile Home Automation-Merging Mobile Value Added Services and Home Automation Technologies. International Conference on the Management of Mobile Business, ICMB, 31-31.

[20] Baek, S.-M., Chang, K.-B., Shim, I.-J. and Park, G.-T. (2004) Implementation of Smart Home Control Using LabVIEW and PDA. IEEE International Symposium on Consumer Electronics, Reading, UK, 1-3 September 2004, 558-562.

[21] National Instruments (2006) LabVIEW ${ }^{\mathrm{TM}}$ Basics Introduction Course Manual.

[22] Halvorsen, H.P. (2011) Introduction to State-Based Applications in LabVIEW.

[23] Labiod, D.H., Afifi, H. and De Santis, C. (2007) Wi-Fi, Bluetooth, ZigBee and WiMAX. Springer Verlag Publisher, Dordrecht, 316. http://dx.doi.org/10.1007/978-1-4020-5397-9 
[24] Hart, J. and Kirk, M. (2006) Environmental Sensor Networks: A Revolution in the Earth System Science? EarthScience Reviews, 78, 177-191. http://dx.doi.org/10.1016/j.earscirev.2006.05.001

[25] Stankovic, J.A. (2008) When Sensor and Actuator Networks Cover the World. ETRI Journal, 30, 627-633.

[26] Varchola, M. (2007) Zigbee Based Home Automation Wireless Sensor Network. Acta Electrotechnica, 7, 1-8.

[27] Jamil, M., Zain, M., Krishnamurthy, V. and Sazonov, E. (2009) Scientific Data Acquisition for Structural Health Monitoring by Using Wireless Intelligent Sensor. European Journal of Scientific Research, 33, 585-593.

[28] Freescale Semiconductor (2009) High Temperature Accuracy Integrated Silicon Pressure Sensor for Measuring Absolute Pressure, On-Chip Signal Conditioned, Temperature Compensated and Calibrated. Technical Report. www.freescale.com

[29] Honeywell (2010) HIH 5030/5031 Series, Low Voltage Humidity Sensors. Technical Report. http://sensing.honeywell.com

[30] Folea, S., Bordencea, D., Hotea, C. and Valean, H. (2012) Smart Home Automation System Using Wi-Fi Low Power Devices. IEEE International Conference on Automation Quality and Testing Robotics (AQTR), Cluj-Napoca, 24-27 May 2012, 569-574.

[31] Microsemi (2005) Ambient Light Detector, LX1972. Technical Report. www.microsemi.com

\section{Submit or recommend next manuscript to SCIRP and we will provide best service for you:}

Accepting pre-submission inquiries through Email, Facebook, Linkedin, Twitter, etc A wide selection of journals (inclusive of 9 subjects, more than 200 journals)

Providing a 24-hour high-quality service

User-friendly online submission system

Fair and swift peer-review system

Efficient typesetting and proofreading procedure

Display of the result of downloads and visits, as well as the number of cited articles

Maximum dissemination of your research work

Submit your manuscript at: http://papersubmission.scirp.org/ 